Özgün Araştırma

Engelli Tuvaletlerinin Uygunluğu ve Kullanımı

\title{
Hacettepe Üniversitesi Merkez Kampüsü Bünyesinde Bulunan Engelli Tuvaletlerinin Uygunluğunun ve Kullanım Durumunun İncelenmesi
}

\author{
Gamze Yıldırım ${ }^{1}$, Hatice Abaoğlu ${ }^{2}$, Hülya Kayıhan ${ }^{2}$, Burcu Semin Akel ${ }^{2}$ \\ ${ }^{1}$ Dışkapı Yıldırım Beyazıt Eğitim ve Araştırma Hastanesi \\ ${ }^{2}$ Hacettepe Üniversitesi, Sağl1k Bilimleri Fakültesi, Ergoterapi Bölümü
}

\begin{abstract}
Özet
$\mathrm{Bu}$ araştırmanın amacı Hacettepe Üniversitesi bünyesinde bulunan engelli tuvaletlerinin uygunluğunu, temizlik ve kullanım durumunu incelemekti. Araştırmaya Hacettepe Üniversitesi Engelli Öğrenci Birimieene kayıtlı olan 42 birey dâhil edildi. Tuvalet ölçümleri Dünya Engelliler Vakfi"nın 2011 yılında yayınladığı "Engelliler İçin Evrensel Standartlar Kılavuzu" temel alınarak araştırmacılar tarafindan oluşturulan 16 maddelik checklist kullanılarak değerlendirildi. Ayrıca tuvaletler, 5 sorudan oluşan anket ile temizlik açısından incelendi. Katılımcılara, engelli tuvaletlerinin kullanım durumunu analiz etmek için yarı yapılandırılmış bir görüşme formu uygulandı. Bu araştırmanın sonucunda, engelli tuvaletlerinin Dünya Engelliler Vakfı standartlarına \%100 uygun olmadığı ve hijyen açısından yetersiz olduğu görüldü. Araştırmaya dâhil edilen öğrencilerin \%11.9"unun engelli tuvaletlerini kullandığı belirlendi. Engelli tuvaletlerinin tercih edilmeme sebebinin daha çok sayı olarak azlığ olduğu tespit edildi. Bulgular 1şığında, üniversitelerde engelliler için standartlara ve hijyen koşullarına uygun öğrenci tuvaletlerinin sayısının artırılması gerektiği vurgulanmaktadır. Tuvalet kullanımını etkileyen bireysel ve çevresel faktörler göz önünde bulundurularak, engelli öğrencilerin ulaşım ve mobilite gereksinimlerine daha fazla önem verilmelidir.
\end{abstract}

Anahtar kelimeler: engelli, günlük yaşam aktiviteleri, üniversite, tuvalet, ögrenci

Sorumlu Yazar: Burcu Semin Akel, Doç. Dr. Hacettepe Üniversitesi Sağlık Bilimleri Fakültesi Ergoterapi Bölümü, 03123052560. semin@ hacettepe.edu.tr 
Original Research

The Suitability and Usage Status of the Disabled Toilets

\title{
The Investigation of the Suitability and Usage Status of the Disabled Toilets Located on Hacettepe University Main Campus
}

\author{
Gamze Yıldırım $^{1}$, Hatice Abaoğlu ${ }^{2}$, Hülya Kayıhan ${ }^{2}$, Burcu Semin Akel ${ }^{2}$ \\ ${ }^{1}$ Diskapi Yildirim Beyazit Training and Research Hospital \\ ${ }^{2}$ Hacettepe Üniversity, Faculty of Health Sciences, Department of Occupational Therapy
}

\begin{abstract}
The aim of this study was to investigate suitability, hygiene and use of the disabled toilets located on Hacettepe University. Forty-two individual from Hacettepe University Disabled Students Unit were enrolled in the study. The disabled toilets standards were evaluated by a 21 item-checklist, which was organized by the researchers based on "Universal Standards Guide for Persons with Disabilities", published by World Disability Union in 2011. In addition, a questionnaire composed of 5 items was used for observation of the toilets in terms of hygiene. In order to analyse the usage status of the disabled toilets, a semi-structured interview form was applied to the participants. At the end of this study, it was concluded that there is a lack of disabled toilets and the disabled toilets were not totally adequate for sanitation conditions and World Disability Union standards. It was determined that $11.9 \%$ of the students who were included in the study used the disabled toilets. The reason that most students didn ${ }^{\text {eet }}$ prefer the disabled toilets was the absence of adequate number of the university- disabled toilets. In light of the findings, it is emphasized that the numbers of the toilets, which are in accordance with standards and hygiene conditions, should be increased in the universities. It can be recommended that more attention needs to be given to the mobility and access requirements of students with disabilities taking into account individual and environmental factors that affect the use of the toilets.
\end{abstract}

Key Words: disabled, activities of daily living, university, toilet, student

Corresponding Authtor: Burcu Semin Akel, Doç.Dr. Hacettepe Üniversity Sağlık Bilimleri Fakültesi Ergoterapi Bölümü 03123052560 semin@ hacettepe.edu.tr 


\section{Giriş}

Engelli, yaralanma ya da fiziksel veya zihinsel bir rahatsızlı nedeniyle bazı hareketleri, duyuları veya işlevleri kısıtlanan kişidir (Soanes ve Stvenson, 2003; Türk Dil Kurumu [TDK], 2011). Engellilik insan olma halinin bir parçasıdır. Neredeyse herkes yaşamının belli bir noktasında geçici veya kalıcı olarak zayıf düşecek ve uzun yıllar yaşayan insanlar işlevlerini yerine getirme konusunda artan zorluklarla karşılaşacaktır. Vücut yapı ve fonksiyonlarında meydana gelen bozukluk, bir görev veya aktivite sırasında zorluk veya kısıtlamaya neden olur ve kişinin günlük rollerine ve aktivitelerine katılımını engeller (Law, 2002).

Günlük Yaşam Aktiviteleri (GYA), toplum tarafından katılımı önemli olan, kişinin her gün, gün içerisinde tipik olarak yaptığı, kendine bakım, giyinme, yemek yeme, banyo yapma, tuvalet hijyeni, uyku, ev temizliği yapma gibi aktivitelerin tümüdür (Letts ve Bosch, 2005). GYA göz önüne alındığında en önemli ve en temel aktivitelerden biri tuvalet kullanımıdır. Engelliler günlük ihtiyaçlarını kendi başlarına sağlamada zorlanırlar ve gelişen tıbbi sorunlar nedeni ile tuvalet ve banyoda daha fazla zaman geçirirler. Bu nedenle planda tuvalet-banyo düzenlemesi önem kazanır (Başbakanlık Özürlüler İdaresi Başkanlığı, 2010).

Üniversitede öğrenci olmak insanları hem geleceğe hem de hayata hazırlar. Gençlik döneminin en önemli sosyal özelliklerinden biri gencin giderek daha bağımsız davranışlar sergilemesidir. Gençlerin ailelerinden daha bağımsız davranışlar geliştirmesi gerçeği, onları yetişkin rollerine yakınlaştırmaktadır. Engelli gençlerin, yemek-içmek, banyo, giyinmek, tuvalet, alışveriş, hareket etmek gibi rutin ihtiyaçlarını ailelerinin ya da herhangi birilerinin yardımını almadan gerçekleştirebilmesi, onun giderek daha bağımsız bir yetişkin rolü kazanmasında etkilidir (Emiroğlu, 2008; Thomas, Bax ve Symth, 1989). Armitage (1983), engelli gençlerin yaşamını bir başkasına ihtiyaç duymadan, bağımsız olarak sürdürebileceği bir ev yaşantısına hazırlanması sürecinin, sosyal çevreye uyum ve bütünleşmelerinde etkili olduğunu belirtir.

Dünya Sağlık Örgütüeenün geliştirdiği İşlevsellik Yetiyitimi ve Sağlığın Uluslararası Sınıflandırması vücut yapı ve fonksiyonları, aktivite ve katılımın yanı sıra kişisel ve çevresel faktörleri de içine alarak, sağlık ve sağlıkla ilişkili durumları kapsamlı bir şekilde ele alır. Sınıflandırma, müdahale planları oluşturulurken, bireyin yaşamında kişisel ve çevresel faktörlerin önemini vurgular. Bireyin yaşama katılımında çevresel faktörler kısıtlayıcı ya da destekleyici olarak rol oynayabilir (World Health Organisation [WHO], 2001). Çevresel düzenlemelerdeki yetersizlikler engelli öğrencilerin eğitimsel, sosyal aktivitelere ve üniversite 
yaşamına katılımını olumsuz yönde etkileyebilmektedir (Redpath ve diğ., 2012).

Burcu (2002), Hacettepe Üniversitesieende öğrenim gören engelli öğrencilerin sorunlarını ve beklentilerini incelediği araştırmanın sonucunda, “Özürlü gençlerin en önemli sıkıntıları kampüsün fiziksel konumu ile ilgilidir. Hem görme hem de bedensel özürlü öğrenciler için, kampüs içi yolların bozuk olması, merdivenlerin çokluğu ve yapısındaki bozukluk dış alanlarda ki problemleri göstermektedir. Ayrıca tuvaletlerin dar olması, sınıf sandalyelerinin öğrencilerin kendi malzemelerim kullanabilecek ya da not alabilecek kadar geniş ve rahat olmaması, bazı sınıflarda ki 1sı problemi, kışın kampüse ve kampüs içinde dersliklere ulaşımın güçlüğü özürlü gençlerin problemleri olarak tespit edilmiştir” ifadesine yer vermiştir. Literatür incelendiğinde, engelli öğrencilerin aktivite katılımını ve yaşam kalitesini etkileyen, fiziksel çevre, mimari düzenlemeler ile ilgili kaynağa ulaş1lırken, üniversite öğrencilerinin önemli günlük yaşam aktivitelerinden biri olan tuvalet kullanımı ile ilgili yeterli araştırmaya rastlanmamıştır. Bu çalışmanın amacı, Hacettepe Üniversitesieende bulunan engelli tuvaletlerinin engelli bireylere uygunluğu ve hijyen koşullarını inceleyerek, engelli tuvaletlerinin kullanım durumunu ve yaşanan güçlükleri değerlendirmektir.

\section{Bireyler ve Yöntem}

$\mathrm{Bu}$ araştırma, Hacettepe Üniversitesi Engelli Öğrenci Birimi ile birlikte yürütüldü. Araştırmaya, Engelli Öğrenci Birimieene kayıtlı olan 109 öğrenciden $42^{\text {ee }}$ si gönüllülük esasına dayalı olarak katıldı. Çalışmaya katılan 42 engelli öğrencinin $25^{\mathrm{ec}} \mathrm{i}$ fiziksel engel, $7^{\text {ee }}$ si görme engeli ve $10^{\text {ee }} \mathrm{u}$ da kronik engel durumuna sahipti.

\section{Tuvalet ölçümleri}

Tuvalet ölçümleri Dünya Engelliler Vakfi"nın (DEV) 2011 yılında yayınladığı "Engelliler İçin Evrensel Standartlar Kılavuzu" temel alınarak araştırmacılar tarafindan oluşturulan 16 maddelik anket kullanıldı (Dünya Engelliler Vakfı [DEV], 2011). Şekil 1, 2 ve

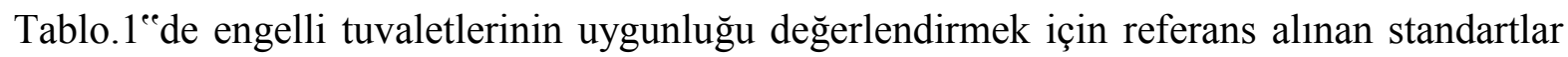
gösterildi. Ayrıca engelli tuvaletleri, oluşturulan 5 soru ile temizlik açısından incelendi. $\mathrm{Bu}$ sorular; klozet için koruyucu malzemeler, sıvı sabun ve tuvalet kağıdının bulunma durumu, klozet temizliğinin ve genel tuvalet temizliğinin yapılıp yapılmadığını içermektedir. 


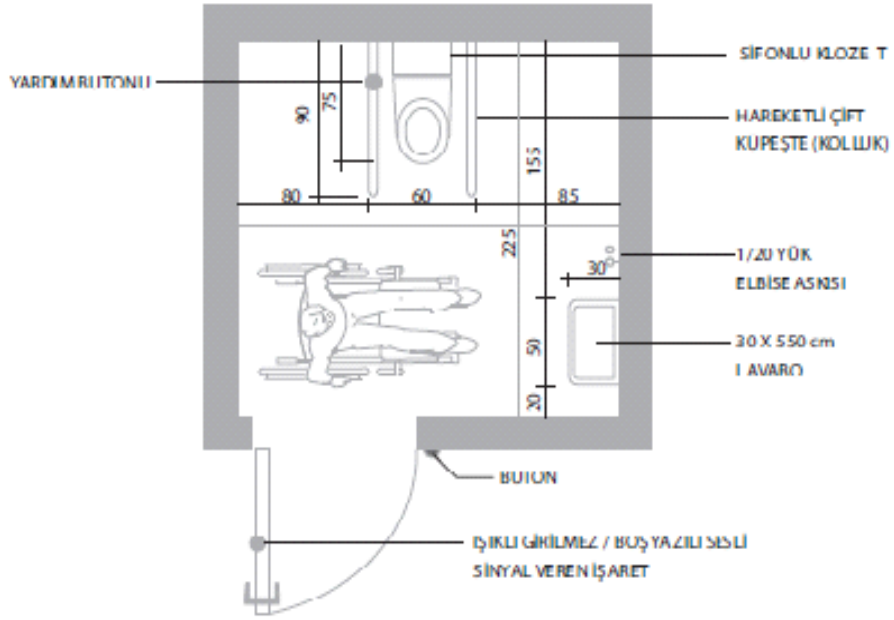

Şekil 1. Tuvalet ve Lavabolar (El Kitab1)

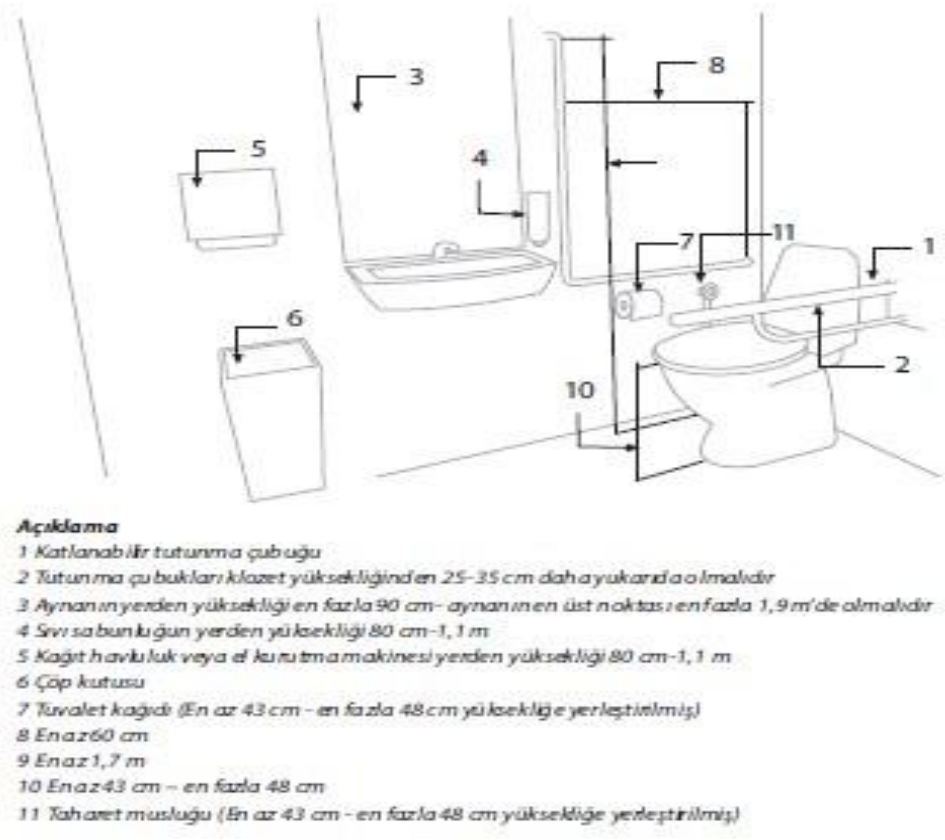

Şekil 2. Tuvalet Örneği (TS 9111) 


\section{Engelli tuvaletlerinin kullanımı anketi}

Araştırmaya dâhil edilen engelli öğrencilerin engelli tuvaletlerini kullanım durumunu incelemek amacıyla araştırmacılar tarafından yarı yapılandırılmış görüşme formu oluşturuldu ve yüz yüze görüşme yöntemi kullanıldı.

Tablo 1. DEV ${ }^{e e}$ in Engelli Tuvaletleri İçin Belirlediği Standartlar (DEV, 2011)

İNCELENECEK OLAN BÖLÜM STANDART ÖLÇÜM

\begin{tabular}{ll}
\hline Genel Tuvalet Ölçümü & En az 220x220 cm \\
\hline Döşeme Seviye Farkı & $0,6 \mathrm{~cm}$ \\
\hline Kapı Genişliği & $>89 \mathrm{~cm}$ \\
\hline Kapının Açıklık Derecesi & $>89^{\circ}$ \\
\hline Klozet Yüksekliği & $43-48 \mathrm{~cm}$ \\
\hline Sifon Yüksekliği & $<1,12 \mathrm{~cm}$ \\
\hline Tuvalet Kâğıtlığı Yüksekliği & $43-45 \mathrm{~cm}$ \\
\hline Tutunma Barı Çapı & $3,2-3,5 \mathrm{~cm}$ \\
\hline Tutunma Barı Yüksekliği & Klozet yüksekliğinden25-35 cm fazla \\
\hline Tutunma Uzunluğu & $>60 \mathrm{~cm}$ \\
\hline Ayna Yüksekliği & $<90 \mathrm{~cm}$ \\
\hline Ayna Üst Noktası & $<190 \mathrm{~cm}$ \\
\hline Bataryaya Erişim Uzaklığı & $<30 \mathrm{~cm}$ \\
\hline Lavabonun Yerden Yüksekliği & $75 \mathrm{~cm}$ \\
\hline Sivı Sabunluk Yüksekliği & $80-110 \mathrm{~cm}$ \\
\hline Kâ̆ı̆t Havluluk ya da Kurutma & $80-110 \mathrm{~cm}$ \\
\hline Makinesi Yüksekliği & \\
\hline
\end{tabular}




\section{Bulgular}

Bu araştırma kapsamında, Hacettepe Üniversitesi Merkez Kampüsüeende bulunan 10 engelli tuvaleti değerlendirmeye alındı. Tıp fakültesinde 5, Ergoterapi Bölümünde 1, Fizik Tedavi ve Rehabilitasyon Bölümünde 2, Eczacılık Fakültesinde 1 ve yemekhanede bulunan 1 engelli tuvaleti araştırma sırasında incelendi. Engelli tuvaletlerinin uygunluğu DEV tarafından belirlenen standartlara göre değerlendirildi.

Yapılan ölçümler sonucunda engelli tuvaletlerinin, döşeme seviye farkı, kapı genişliği, kapı açıklık derecesi, sifon yüksekliği, tutunma barı uzunluğu, ayna üst noktası ve bataryaya erişim açısından standartlara uygun olduğu görüldü. Değerlendirilen engelli tuvaletlerinin tamamının tuvalet kâğıdı yüksekliği, tutunma barı çapı, lavabo yerden yüksekliği ve kâğıt havluluk/kurutma makinesi yüksekliği açısından DEV standartlarına uygun olmadığı

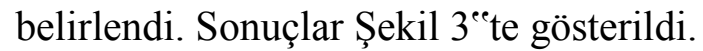

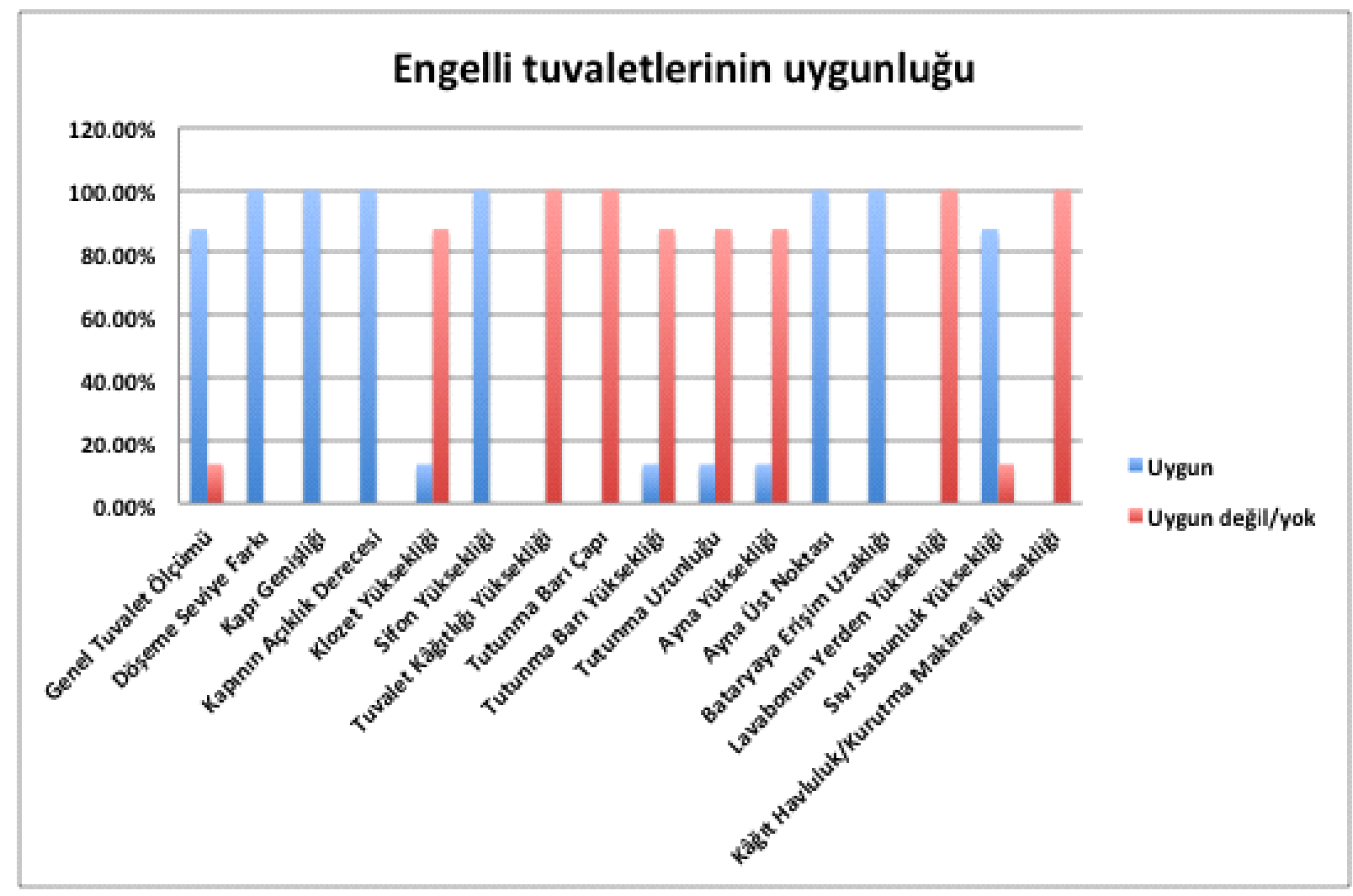

Şekil 3. Hacettepe Üniversitesi Merkez Kampüsünde Bulunan Engelli Tuvaletlerinin Genel Durumlarının Yüzdelik Oranları 
Yapılan ölçümler sonucunda engelli tuvaletlerinin genel uygunluk düzeyi $\% 51,56$ olarak belirlendi. Engelli tuvaletleri hijyen özellikleri, klozet koruyucu malzemeler, tuvalet kâğıdı ve sıvı sabun varlığı, klozet temizliği ve genel tuvalet temizliği açısından değerlendirildi. Tuvaletlerin genel temizlik durumu oranları Şekil.4te gösterildi.

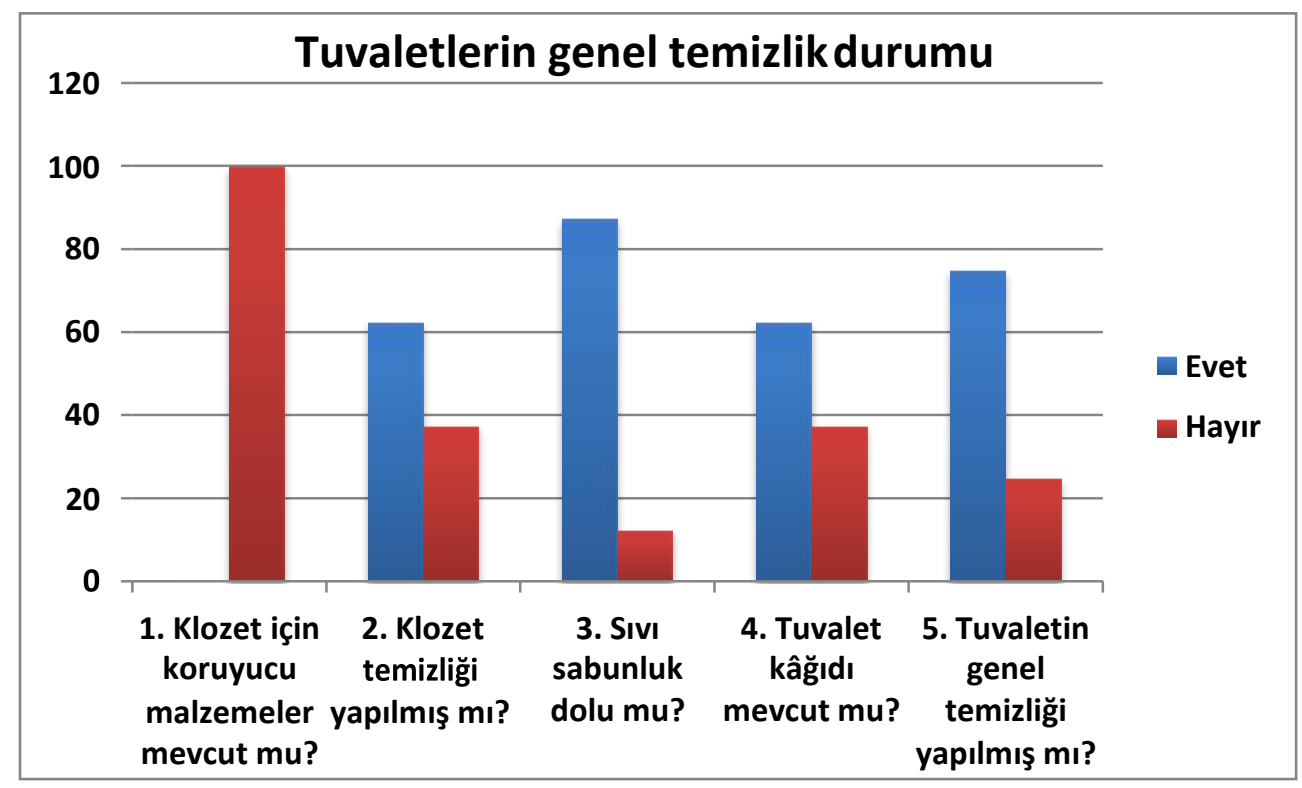

Şekil 4. Hacettepe Üniversitesi Merkez Kampüsünde Bulunan Engelli Tuvaletlerinin Temizlik Durumunun Yüzdelik Oranları

Araştırmaya dâhil edilen 42 engelli öğrenci arasında yapılan Engelli Tuvaletleri Kullanım Değerlendirme Anketi sonuçlarına göre, engelli tuvaletlerinin büyük bir oranda kullanılmadığı tespit edildi. Bireylerin $\% 11,9^{e e} u$ engelli tuvaletlerini kullandığı, engelli tuvaletlerini kullanan bu bireylerin tamamının aynı zamanda normal tuvaletleri de kullandığı görüldü. Anket uygulaması sonucunda, tuvaletlerin temiz olmaması ve her yerde bulunmaması öğrencilerin engelli tuvaletlerini tercih etmemelerindeki en önemli sebepler olduğu belirlendi.

Engelli tuvaletlerini kullanan öğrencilerin tamamı tuvalet genişlikleri ve lavabo yüksekliğinin ideal düzeyde olduğu ifade etti. Engelli tuvaletleri, ulaşım, giriş ve kullanım açısından sorgulandığında, öğrencilerin $\% 20^{\text {ee }}$ si tuvaletleri kullanırken, $\% 60^{\text {ee }} 1$ tuvalete giderken, $\% 40^{e e} 1$ ise tuvalet kapısından içeri girerken sorun yaşadığııı belirtti.

Çalışmaya katılan öğrenciler (n:42) arasından \%52 si tuvaletleri hijyenik bulurken, \%48 tuvaletlerin temiz olmadığını söyledi. Öğrencilerin $16^{\text {ee }} \mathrm{s} 1$ (\%38) belirli bir tuvaleti kullanmak istemediğini söyledi. Neden olarak da tuvaletlerin pis olduğunu, bazı tuvaletlerin koktuğunu ya da bazı tuvaletlerde klozetlerin olmasını neden gösterdi. 


\section{Tartışma ve Sonuç}

Engellilerin, yaşamın birçok alanında güçlük yaşamakta oldukları bilinmektedir. Engelli öğrenci olmak bireyi fiziksel ve psikososyal yönden etkileyen ve mücadele gerektiren bir durumdur. Engelli öğrencilerin ihtiyaçları karşılanmadığında ve çevresel engeller nedeniyle kısıtlandıklarında toplumda görünmez hale gelebilirler (Officer ve Shakespeare, 2013). Goode (2007), bir üniversitede öğrenim gören 10 engelli öğrenci ile video kayıtları ve görüşme yoluyla yaptığı araştırmada, üniversite öğrencilerinin engellilikle başa çıkma durumlarını incelemiş ve ailelerinden bağımsız olarak başarı hissinin onlar için oldukça önemli olduğu sonucuna varmıştır. Bu düşünceden yola çıkılarak, bu araştırmada, temel günlük yaşam aktivitelerinden biri olan tuvalet aktivitesinin gerçekleştirilmesi için üniversitede yer alan engelli tuvaletlerinin engelli öğrenciler için uygunluğu ve engelli öğrencilerin engelli tuvaletlerini kullanma durumu incelendi.

Engelli bireyler için kaygan bir zemine sahip tuvaletlerde özellikle tuvalete transfer ve tuvaletten kalkma sırasında tutunma barları çok önemlidir. Araştırma bulgularına göre, tutunma barlarının yükseklikleri uygun ancak kavrama sıkıntısı olan engelli bireyler için önemli olan tutunma barlarının çapı, engelli tuvaletlerinin hiçbirinde standarda uygun değildir. İyi ve kuvvetli kavrama için en uygun çap $5 \mathrm{~cm}$ olarak belirlenmiştir. Çengel tutmada çok dar ya da çok geniş saplar kavrama gücünü azaltır (Ulu, 2011). Tutunma barları planlanırken sadece barların yüksekliği değil çapları da dikkate alınmalıdır.

Tuvalet aktivitesinin en önemli parçalarından biri olan el yıkama aktivitesinin gerçekleştirilmesi için gerekli olan lavabo ve sıvı sabunluk, TS kullanan bireyler için ideal bir yükseklikte olmalıdır. Yapılan değerlendirmeler sonucunda tuvaletlerde bulunan lavaboların hiçbirinin standarda uymadığı görülmüştür. Bununla beraber engellilerin ulaşabileceği özel tasarımlarla yapılan bataryaların hepsi engelli bireyler için uygundur. Sıvı sabunlukların yüksekliği ise, engelli tuvaletlerinin \%87,5 inde (n:7) uygun olarak ölçülmüştür. El yıkama

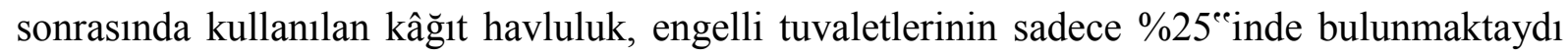
ve bunlarda $\mathrm{DEV}^{\mathrm{ee}}$ in belirlediği standarda uygundeğildi.

Engelli tuvaletlerinin temizlik açısından değerlendirildiğinde engelli tuvaletlerinin hiçbirinde klozet için özel koruyucu malzemeler bulunmadığı görüldü. Engelli bireylerle yapılan görüşmelerin birinde koruyucu malzemeler ile ilgili durumu engelli öğrencimiz şu sözlerle açıklamıştır. 
"Tuvaletlerin temizliği genel olarak yapıllyor ama klozetlere otururken kendimi rahat hissetmiyorum. Koruyucu malzeme olsa daha sık engelli tuvaletini kullanırım.”

$\mathrm{Bu}$ açıklama 1şı̆̆ında engelli bireylerin engelli tuvaletlerini kullanmak istememesinin önemli nedenlerinden biri olarak klozetlerin kullanımıyla alakalı bir problem olduğunu görmekteyiz.

Engelli tuvaletlerinde tuvalet kâğıtlarının mevcudiyetiyle alakalı yapılan

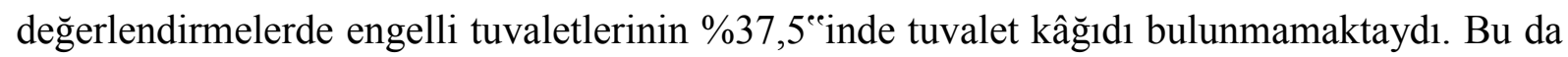
kişisel temizliğin gerçekleştirilmesinde bireyler için büyük bir sıkıntı oluşturmaktadır. Engelli tuvaletlerini kullanan öğrencilerden tuvaletlerin temizlik durumlarını değerlendirmelerini istendiğinde, öğrencilerin $\% 48^{e ` i}$ engelli tuvaletlerini hijyen açısından uygun bulmadığ görülmüştür.

Kitchin (1998), engelliliği sosyal ve boyutsal açıdan incelediği derlemesinde, toplumsal alanlarda engellilerin ötekileştirilerek hariç tutulduğunu ifade etmiştir. Derlemede, topluma açık engelli ulaşılabilir tuvaletlerin sağlıklı tuvaletlerinden ayrı tutulduğu, cinsiyete özel tasarlanmadığı ve genellikle kilitli tutularak ulaşılabilirliğinin kısıtlandığı vurgulanmaktadir.

Araştırmamızda, engelli tuvaletlerinin kullanım durumu değerlendirildiğinde, bireylerin sadece $\% 11,9^{e c} \mathrm{u}(\mathrm{n}: 5)$ engelli tuvaletlerini kullandığı sonucu ortaya çıkmıştır. Engelli tuvaletini kullanan bireylerin hepsi aynı zamanda normal tuvaletleri de kullanmaktadır. Yapılan görüşmeler sonucunda, öğrencilerin $\% 38^{\text {ee }} \mathrm{i}$ belirli bir tuvaleti kullanmak istemediğini söylemiştir. Nedeni sorulduğunda genel olarak "Tuvaletler pis", “Tuvaletler kokuyor”, "Klozet olduğundan kullanmaktan çekiniyorum” cevapları alınmıştır.

Engelli tuvaletini kullanmama nedenini bir öğrenci şu sözlerle belirtmiştir;

"Tuvalet çok pis. Ayrıca engelli tuvaleti de her yerde yok o yüzden en yakında olan normal tuvaleti kullanıyorum. Engelli tuvaletleri her normal tuvaletinin yanına yapılmall."

2011 yılında Hacettepe Üniversitesi Engelli Öğrenci Biriminin yaptığı bir çalışma, engelli tuvaletlerinin neden kullanılmadığını gözler önüne sermiştir. Çalışma sonucunda "Eğitim binaları ve hastanelerdeki engelli tuvalet sayısının çok az olması ve bulunan tuvaletlerin temiz olmaması öğrenciler tarafından dile getirilmektedir." ifadesi sonuç bölümünde bulunmaktadır. Çalışmamız engelli tuvaletlerinin engelli bireyler tarafından kullanılmadığını göstermiştir. Tuvaletlerin kullanılmama nedeninin tuvaletlerin mimari sıkıntılarından çok bireysel temizlik yapmada zorluklar olduğunu ve sayısının az olduğu ortaya konulmuştur. Temizliklerinden emin olunamadığı için tercih edilmeyen engelli 
tuvaletlerindeki klozetlerin koruyucu malzemelerle temizliğinin sağlanması gereklidir. Özellikle tekerlekli sandalyeden klozete transfer olması gereken bireyler için bu koruyucu malzemelerin serme şeklinde değil, kollu olanları tercih edilmelidir.

Engelli tuvaletlerinin çok tercih edilmemesinin nedenleri arasında engelli tuvaletlerinin sayısının azlığı gösterilmektedir. Bu nedenle engelli tuvaletlerinin üniversite kapsamında artırılması sorunun çözülmesine katkı sağlayacaktır. Engelli bireylerin kendileri için özel tasarlanan tuvaletleri kullanabilmelerinde çevresel faktörler önemli rol oynamaktadır. Tuvaletlerinin standartlara ve engelli bireylere uygunluğunu sağlamak amacıyla ergoterapistler ve ilgili diğer tüm meslek grupları, engelli bireyler, kuruluşlar ve toplum işbirliği içerisinde çalışarak gereken sorumluluğu almalıdır. 


\section{Kaynakça}

Armitage, J. (1983), Barriers: A survey of housing physical disability and the role of local authorities, London: SHELTER- National campaign for the homeless.

Burcu, E. (2002). Üniversitede okuyan özürlü öğrencilerin sorunları: Hacettepe Beytepe kampüsü öğrencileri örneği. Hacettepe Üniversitesi Edebiyat Fakültesi Dergisi, 19 (1), 83-103.

Emiroğlu, B. G. (2008). Üniversitelerde görme engelli öğrenciler için bilişim. X. Akademik Bilişim Konferansı, (30Ocak-1Şubat, 2008), Çanakkale On Sekiz Mart Üniversitesi, Çanakkale.

Goode, J. (2007) „Managinge disability: early experiences of university students with disabilities. Disability and Society, 22 (1), 35-48.

Hacettepe Üniversitesi Engelli Öğrenci Birimi Çalışma Raporu, Ekim 2010 http://www.eob.hacettepe.edu.tr/Yok_rapor1_180411.pdf_sitesinden elde edilmiştir.

Kitchin, R. (1998) 'Out of place', 'knowing one's place': space, power and the exclusion of disabled people, Disability and Society, 13(3), 343-356.

Koca, C. (2010). Engelsiz Şehir Planlaması Bilgilendirme Raporu. İstanbul: Dünya Engelliler Vakfi. http://www.devturkiye.org/upload/filev/engellilerictasarım.pdf

Law, M. (2002). Participation in the occupations of everyday life. The American Journal of Occupational Therapy, 56(6), 640-649.

Law, M. (2002). Participation in the occupations of everyday life. The American Journal of Occupational Therapy, 56(6), 640-649. Ulu H. (2011). İşle ilgili üst ekstremite kas iskelet sistemi problemi olan ev kadınlarında kişi merkezli ergoterapi eğitiminin aktivite performansı, özür ve stres düzeyi üzerine etkisi.

Letts, L., \& Bosch, J. (2001). Measuring occupational performance in Basic Activities of Daily Living. In M. Law, C. Baum, \& W. Dunn (Eds.), Measuring Occupational Performance (pp. 129-226). Thorofare, NJ: SLACK Incorporated.

Officer, A., \& Shakespeare, T. (2013). The world report on disability and people with intellectual disabilities. Journal of Policy and Practice in Intellectual Disabilities, 10 (2), 86- 88.

Redpath, J., Kearney, P., Nicholl, P., Mulvenna, M., Wallace, J., \& Martin, S. (2012). A qualitative study of the lived experiences of disabled post-transition students in higher education institutions in Northern Ireland. Studies in Higher Education, 38 (9), 1334-1350.

Soanes, C. \& Stvenson, A. (2003). Oxford Dictionary of English. Oxford University Press, Oxford, U.K.

T.C. Başbakanlık Özürlüler İdaresi Başkanlığı. (2002).Türkiye Özürlüler Araştırması Temel Göstergeleri, Ankara.

TDK Sözlük (2011). Büyük Türkçe Sözlük. http://tdkterim.gov.tr/bts adresinden 06/10/2011 tarihinde indirilmiştir.

Thomas, A., Bax, M. \& Smyth, D. (1989). The Health and Social Needs of Young Adults With Physical Disabilities. MacKeith Press, Blackwell Scientific Publications Ltd, Oxford.

World Health Organisation. (2001). International classification of functioning, disability and health; World Health Organisation: Geneva, Switzerland. 